\title{
Development of a longterm dataset of solid/liquid precipitation
}

\author{
B. Chimani, R. Böhm, C. Matulla, and M. Ganekind \\ Central Institute for Meteorology and Geodynamics, Vienna, Austria
}

Received: 14 December 2010 - Revised: 21 February 2011 - Accepted: 22 February 2011 - Published: 28 February 2011

\begin{abstract}
Solid precipitation (mainly snow, but snow and ice pellets or hail as well), is an important parameter for climate studies. But as this parameter usually is not available operationally before the second part of the 20th century and nowadays is not reported by automatic stations, information usable for long term climate studies is rare. Therefore a proxy for the fraction of solid precipitation based on a nonlinear relationship between the percentage of solid precipitation and monthly mean temperature was developed for the Greater Alpine Region of Europe and applied to the existing longterm high resolution temperature and precipitation grids ( 5 arcmin). In this paper the method is introduced and some examples of the resulting datasets available at monthly resolution for 1800-2003 are given.
\end{abstract}

\section{Introduction}

The ratio of solid to total precipitation has been part of the routine meteorological observing and digitizing programmes of weather services for several decades of the 20th century. Back into the 19th century and further back into the early instrumental period (e.g. Böhm et al., 2010) such data are not available at daily resolution and least of all in homogenized form (e.g. Moberg et al., 2006). In recent decades automation of the networks makes the splitting of precipitation into its solid and liquid parts vanishing more and more from the observing practice due to typical automated networks without observers. Therefore an increasing lack of such parameters which are either not or expensive to automate is going to cause deficiencies for research and practical applications in the future. Nevertheless solid precipitation is an important climate parameter in terms of practical applications and a parameter sensitive to the ongoing and anticipated warming.

In this paper we want to introduce a method to produce "instrumental based proxies" for the solid/liquid precipitation fractions and for totals of solid/liquid precipitation derived from monthly mean temperatures and monthly precipitation totals. The derived method is applied on the existing high-resolution longterm grids of these two basic climate parameters (Efthymiadis et al., 2006; Chimani et al., 2010) in the "Greater Alpine Region" (henceforth GAR), which

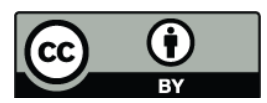

Correspondence to: B. Chimani (barbara.chimani@zamg.ac.at) reaches from $4^{\circ}-19^{\circ} \mathrm{E}$ and $43^{\circ}-49^{\circ} \mathrm{N}$ (Auer et al., 2005, 2007). The resulting new datasets provide monthly, seasonal and annual solid/liquid precipitation totals back to 1800 and the monthly ratios of solid/liquid precipitation back to 1780 - at a spatial resolution of 5 arcmin which may be the maximum possible resolution in terms of the given network density. This resolution is adequate for a considerable number of scientific and practical applications in the topographically complex terrain of the study region.

As a positive side effect the method of "instrumental based proxies" - if applied on well homogenizable monthly input data - produces "indirectly homogenized" time series of climate parameters elsewise hardly homogenizable directly.

In Sect. 2 the method for deriving the percentage and amount of solid precipitation is introduced, Sect. 3 shows some results achieved with this new dataset. The conclusions are summarized in Sect. 4.

\section{Method}

\subsection{Derivation of the relationship between monthly mean temperature and the percentage of solid precipitation}

Daily measurements of temperature, precipitation amount and precipitation type of more than 170 stations in Austria for 1950 to 2008 were used to analyze and describe a relationship between the mean monthly temperature and the monthly percentage of solid precipitation. This was done by determining a hyperbolic tangent. A hyperbolic tangent is a suitable type of function when a parameter with an upper and 
Table 1. Root mean square error (RMSE) of the calculated to the measured percentages of solid precipitation for each month over the period 1950-2008.

\begin{tabular}{lr}
\hline & RMSE \\
\hline January & 24.99 \\
February & 21.84 \\
March & 20.83 \\
April & 14.97 \\
May & 9.09 \\
June & 5.93 \\
July & 5.29 \\
August & 4.93 \\
September & 5.85 \\
October & 12.23 \\
November & 21.13 \\
December & 24.26 \\
\hline
\end{tabular}

a lower limit has to be regressed versus an unlimited one. In our case the percentage of solid precipitation is variable between $100 \%$ (at lower temperatures) and $0 \%$ (at higher temperatures). A similar approach has been successfully applied already on snowcover duration vs. temperature (Hantel et al., 2000; Wielke et al., 2004). The function of the form

$p=50 \tanh \left(2 a_{1}\left(T-a_{2}\right)\right)+50$

with $p$ as solid precipitation fraction in $\%, T$ as temperature in ${ }^{\circ} \mathrm{C}$, and $a_{1}$ and $a_{2}$ being the factors describing the maximum slope and the offset of the function from $0{ }^{\circ} \mathrm{C}$ at the inflection point. The regressions were determined for each single month. A further splitting of the data for example into different climate regions or height layers did not improve the relationship significantly but caused problems due to too few data in some of the resulting classes. The function was determined by minimizing weighted differences of monthly mean temperature and the percentage of solid precipitation (Eqs. 2 and 3 ) between the function and the measurements.

$w \frac{\mathrm{MSE}_{\mathrm{RR}}}{\Sigma(\mathrm{MSE})} \mathrm{MSE}_{\mathrm{T}}+(1-w) \frac{\mathrm{MSE}_{\mathrm{T}}}{\Sigma(\mathrm{MSE})} \mathrm{MSE}_{\mathrm{RR}} \rightarrow \mathrm{Min}$

$w=\frac{n_{>10}}{n_{\mathrm{all}}}$

$w$ is the weighting factor determined by the number $(n)$ of the measurements having more than $10 \%$ of solid precipitation and the number of all measurements, MSE the mean squared error for temperature $\left(_{\mathrm{T}}\right)$ and percentage of solid precipitation (RR) and $\Sigma(\mathrm{MSE})$ the sum of both.

The weighting was necessary due to the different distributions of the percentage of solid precipitation in the different months, especially as in the summer months only low values of solid precipitation occur. The RMSE (root mean square error) of the function for all months can be seen in Table 1. Its maximum lies in January with about $25 \%$ and the minimum in August with 5\%. This is due to the greater variability in the data during winter. It can be noticed by Fig. 1 (left side) that the functions determined for winter months have a steeper slope than the ones for summer times. The right hand side of Fig. 1 shows the data and the fitted tanh-function for January.

\subsection{Generating the longterm dataset of solid precipitation}

In order to gain high resolution monthly fields of the percentage of solid precipitation for the last 200 years for GAR the monthly hyperbolic tangents of Sect. 2.1 were applied to the recently produced long term temperature dataset in the region. This dataset covers a period from 1780 to 2008 at a resolution of $5 \mathrm{arcmin}$. It was created by blending highly resolved monthly mean temperature grids 1961-1990 of the region (Hiebl et al., 2009) with longterm lower resolution anomaly fields in two different height layers to account for the decoupling of atmospheric layers e.g. due to inversions. To provide a comparable spatial resolution of the data over the whole period missing parts of the station-mode series were reconstructed by an EOF-method. For details see Chimani et al. (2010).

Moreover a regional high resolution longterm absolute monthly precipitation dataset was used to generate information not only about the percentage of solid precipitation over the last 200 years but also for the solid/liquid totals in $\mathrm{mm}$. For details of the underlying precipitation dataset see Efthymiadis et al. (2006). It covers the period from 1800 to 2003. This dataset covers the same region as the long term temperature dataset and had only to be rescaled from $10^{\prime}$ to the aspired $5^{\prime}$ grid resolution. This rescaling was done by a straightforward approach without introducing additional information. As no precipitation dataset, developed on a 5-min grid, was available for the whole GAR the additional uncertainties had to be accepted.

\section{Results}

Figure 2 shows an example of the resulting fields of the percentage and the amount of the solid precipitation for December 1929. In the image of the percentage of solid precipitation (Fig. 2a) the high percentage on the Alpine ridge, due to locally low temperatures, can be seen. The Apennine, the Dinaric Alps and the Jura can also be identified easily. Moreover the continental influence in the eastern part of the GAR compared to the western part can be noticed by the smaller percentage of solid precipitation in the west and especially near the Mediterranean. The structure of the amount of solid precipitation (in mm water equivalent) (Fig. 2b) shows a similar picture with a higher amount of solid precipitation in the mountainous regions but especially north of the Alps the areas of higher solid precipitation amount extends farther north than the percentage alone would explain. Here the influence of the precipitation distribution is visible. 

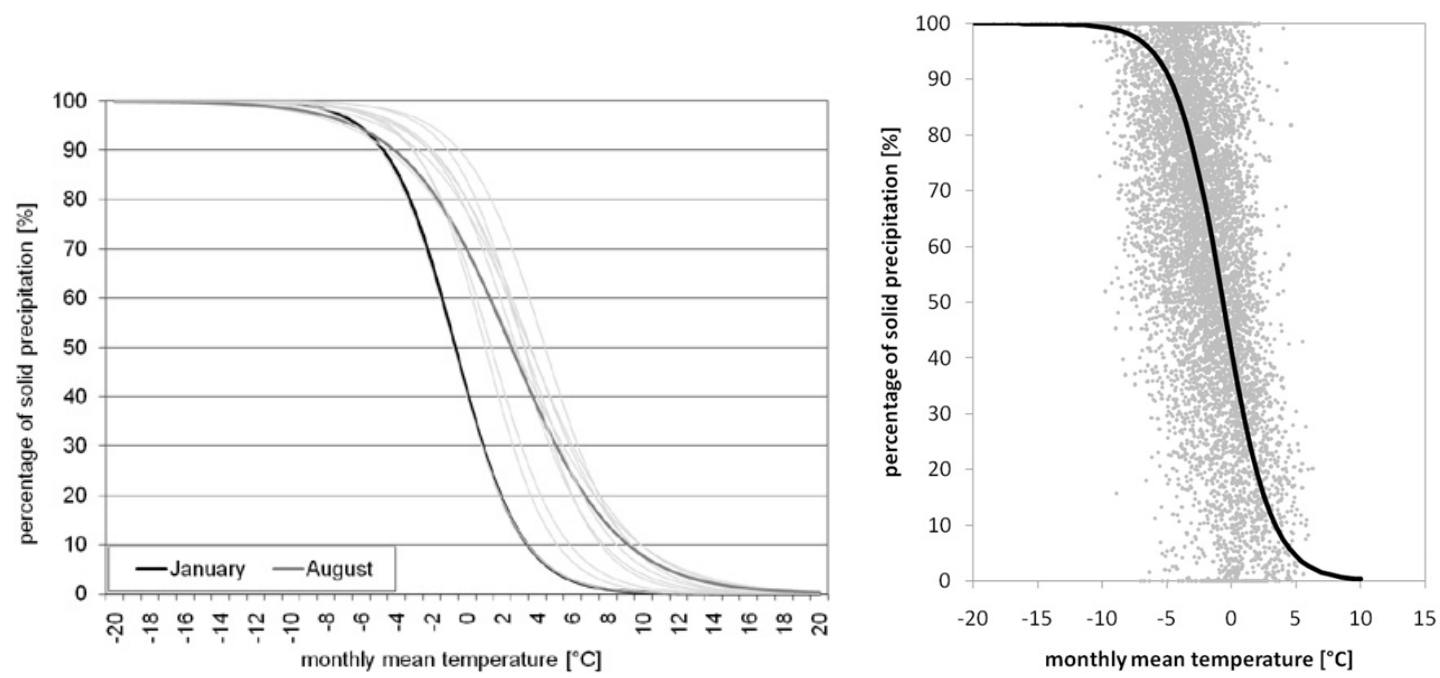

Figure 1. Left: Hyperbolic tangent function describing the relationship between the monthly mean temperature [ $\left.{ }^{\circ} \mathrm{C}\right]($ abscissa) and the percentage of solid precipitation [\%] (ordinate) for January (black line) and August (dark grey line). Thin light grey lines show the functions for all the other months. Right: Example of the function fitting for January. The black line shows the fitted function and the grey dots the measurements.
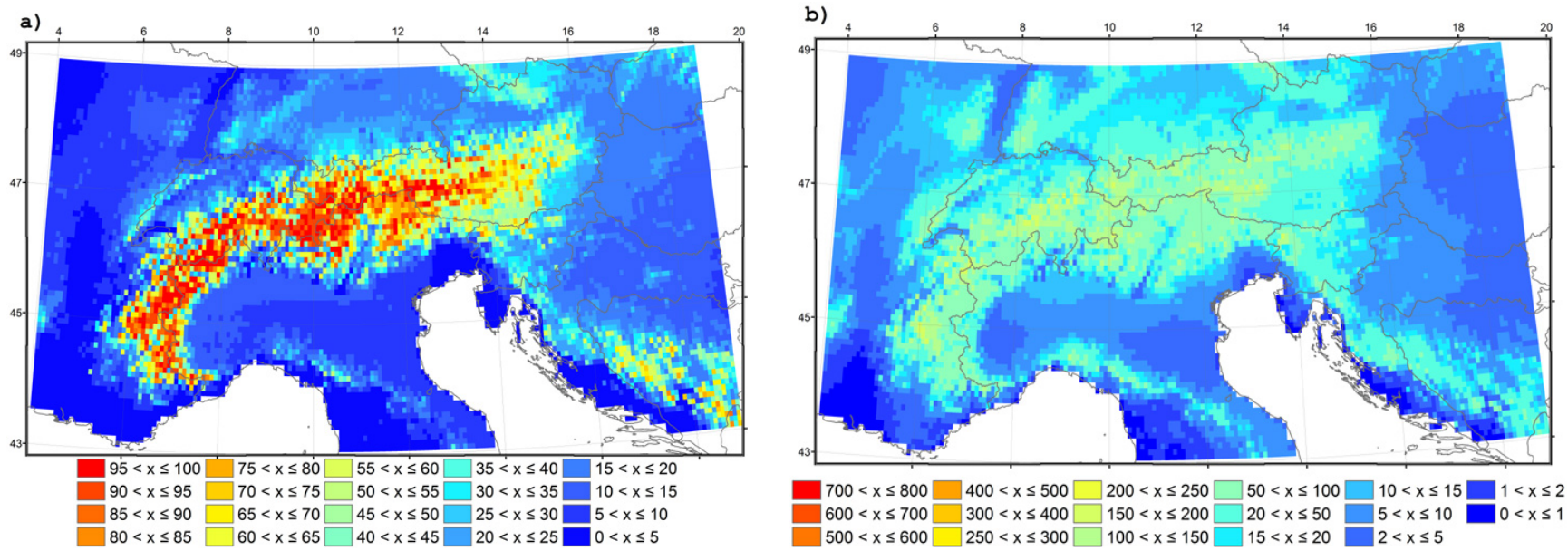

Figure 2. Percentage [\%] (a) and amount [mm water equivalent] (b) of solid precipitation in the GAR for December 1929. Red/blue colours representing high/low values.

Figure 3 displays time series of 11 year running means of the totals and of the percentages of solid winter precipitation of some grid points in the GAR. Nearly no longterm trend in the percentage of solid precipitation can be seen for the inneralpine city of Innsbruck whereas the totals of solid precipitation show marked decadal variations with periods of small amounts of solid precipitation near 1855, 1935 and 1970. The lowest values can be found during the $1855 \mathrm{~min}$ imum. The series of the lower and extra-alpine city of Vienna however show opposite features: Higher decadal scale variablility and also longterm decreasing trend of the per- centage of solid precipitation and smoother time series of the solid precipitation totals. Another interesting structure shown by these plots is the higher percentage of solid precipitation for south-inner-alpine Bozen, compared to the relatively low solid precipitation fractions in the milder northernextra-alpine Zürich, a site with significantly more total precipitation and therefore comparable sums of solid precipitation. 


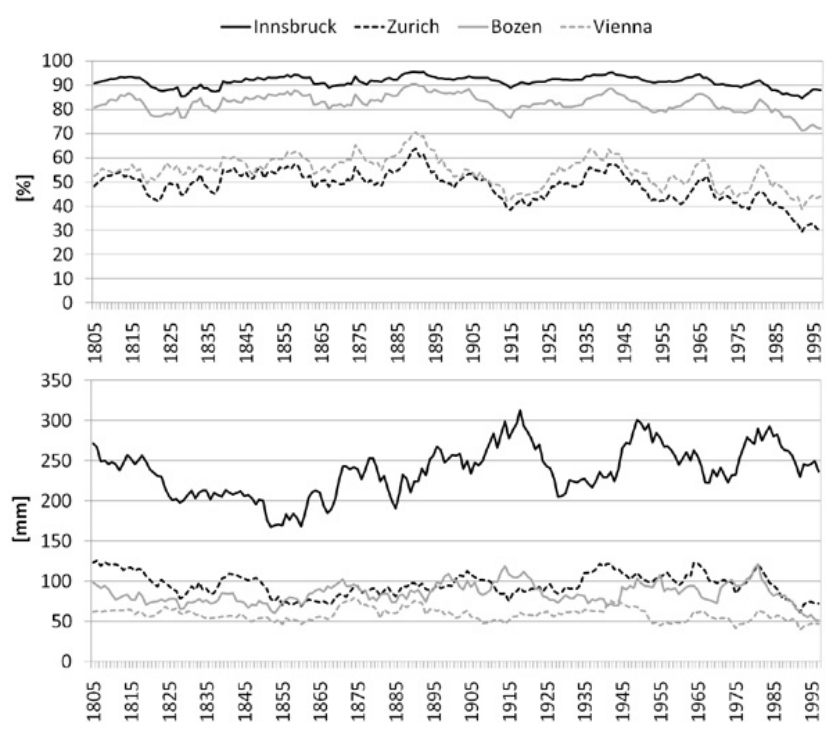

Figure 3. Time series of the 11 year running mean for the percentage [\%] (upper plot) and amount [mm water equivalent] (lower plot) of solid precipitation for winter seasons (DJF). Displayed are the time series of 4 gridpoints located near the cities Innsbruck (black solid line), Zurich (black broken line), Bozen (grey solid line) and Vienna (grey broken line).

\section{Conclusions}

A method was developed to overcome the lack of information about solid precipitation in former centuries and due to the recent automation of measuring networks. The method is based on high resolution monthly temperature and precipitation data and a monthly relationship between mean temperature and the percentage of solid precipitation. We introduced the term "instrumental proxies" for such a type of climate parameters which for longer timescales are not existing directly but maybe indirectly derived from other main climate parameters available in homogenized form for the entire instrumental period. In our case we achieve monthly information for both, the percentage and the amount of solid precipitation for the Greater Alpine Region for the period 1800 to 2003. The spatial resolution is 5 arcmin.

As shown at a few examples here there is a wide field of potential scientific and practical applications using either a map-based approach to study the spatial distribution of solid precipitation or a time series approach to study longterm trends and decadal to annual scale variability for single sites as well as for subregions selected according to specific objectives.

In our opinion the relationship between solid precipitation ratios and temperature should be robust to spatial variations. Nevertheless it might be advisable to define an adequate relationship between monthly mean temperature and the percentage of solid precipitation for different regions as regional specifics like inversion layers could influence the results. As it is necessary to have measurements of the solid precipitation to define the relationship, this might lead to some problems.

Acknowledgements. The dataset was developed in the context of the internal project GAR-SCHNEE-200 of the Central Institute for Meteorology and Geodynamics, Vienna, funded by the Austrian Ministry for Science and Research.

Edited by: M. Dolinar

Reviewed by: two anonymous referees

\section{SC $\mid$ nat $^{\mathbf{t}} \begin{aligned} & \text { The publication of this article is sponsored } \\ & \text { by the Swiss Academy of Sciences. }\end{aligned}$}

\section{References}

Auer, I., Böhm, R., Jurković, A., Orlik, A., Potzmann, R., Schöner, W., Ungersböck, M., Brunetti, M., Nanni, T., Maugeri, M., Briffa, K., Jones, P., Efthymiadis, D., Mestre, O., Moisselin, J.M., Begert, M., Brazdil, R., Bochnicek, O., Cegnar, T., GajićČapka, M., Zaninović, K., Majstorović, Ž., Szentimrey, T., and Mercalli, L.: A new instrumental precipitation dataset for the Greater Alpine Region for the period 1800-2002, Int. J. Climatol., 25, 139-166, 2005.

Auer, I., Böhm, R., Jurkovic, A., Lipa, W., Orlik, A., Potzmann, R., Schöner, W., Ungersböck, M., Matulla, C., Briffa, K., Jones, P., Efthymiadis, D., Brunetti, M., Nanni, T., Maugeri, M., Mercalli, L., Mestre, O., Moisselin, J.-M., Begert, M., MüllerWestermeier, G., Kveton, V., Bochnicek, O., Stastny, P., Lapin, M., Szalai, S., Szentimrey, T., Cegnar, T., Dolinar, M., GajicCapka, M., Zaninovic, K., Majstorovic, Z., and Nieplova, E.: HISTALP-Historical instrumental climatological surface time series of the Greater Alpine Region 1760-2003, Int. J. Climatol., 27, 17-46, 2007.

Böhm, R., Jones, P. D., Hiebl, J., Frank, D., Brunetti, M., and Maugeri, M.: The early instrumental warm-bias: a solution for long central European temperature series 1760-2007, Clim. Change, 101, 41-67, 2010.

Chimani, B., Matulla, C., Böhm, R., and Hofstätter, M.: A new high resolution absolute Temperature Grid for the Greater Alpine Region back to 1780, Int. J. Climatol., submitted, 2010.

Efthymiadis, D., Jones, P. D., Briffa, K. R., Auer, I., Böhm, R., Schöner, W., Frei, C., and Schmidli, J.: Construction of a 10-min-gridded precipitation data set for the Greater Alpine Region for 1800-2003, J. Geophys. Res., 111, D01005, doi:10.1029/2005JD006120, 2006.

Hantel, M., Ehrendorfer M., and Haslinger A.: Climate sensitivity of snow cover duration in Austria, Int. J. Climatol., 20, 615-640, 2000.

Hiebl, J., Auer, I., Böhm, R., Schöner, W., Maugeri, M., Lentini, G., Spinoni, J., Brunett, M., Nanni, T., Tadić, M. P., Bihari, Z., Dolinar, M., and Müller-Westermeier, G.: A high-resolution 1961-1990 monthly temperature climatology for the greater Alpine region, Meteorol. Z., 18(5), 507-530, 2009. 
Moberg, A., Jones, P. D., Lister, D., Walther, A., Brunet, M., Jacobeit, J., Alexander, L. V., Della-Marta, P. M., Luterbacher, J., Yiou, P., Chen, D., Klein Tank, A. M. G., Saladié, O., Sigró, J., Aguilar, E., Alexandersson, H., Almarza, C., Auer, I., Barriendos, M., Begert, M., Bergström, H., Böhm, R., Butler, C. J., Caesar, J., Drebs, A., Founda, D., Gerstengarbe, F.W., Micela, G., Maugeri, M., Österle, H., Pandzic, K., Petrakis, M., Srnec, L., Tolasz, R., Tuomenvirta, H., Werner, P. C., Linderholm, H., Philipp, A., Wanner, H., and Xoplaki, E.: Indices for daily temperature and precipitation extremes in Europe analyzed for the period 1901-2000, J. Geophys. Res., 111, D22106, doi:10.1029/2006JD007103, 2006.

Wielke, L.-M., Haimberger, L., and Hantel, M.: Snow cover duration in Switzerland compared to Austria, Meteorol. Z., 13, 1317, 2004. 